\title{
Editorial Special Issue on "Operations Research and Accounting in Supply Chain Coordination"
}

\author{
Anil Arya - Stefan Minner • Thomas Pfeiffer
}

Published online: 2 November 2013

(C) Springer-Verlag Berlin Heidelberg 2013

The coordination of supply chains has been intensely investigated over the last decade. Several concepts from other disciplines, in particular microeconomic contract analysis, were adapted to supply chain applications. However, within business administration, there are still rather parallel developments between the disciplines of management accounting and supply chain management. The aim of this special issue is to stimulate innovative research that uses operations research methodology to combine approaches from both fields at the accounting-operations interface and to provide new managerial insights into the field of supply chain coordination.

The special issue contains six contributions. The first two contributions investigate principal-agent problems with inherent risk-incentive trade-offs. The third contribution combines forecasts and accounting information in a closed-loop supply chain application. The other two contributions analyze specific supply chain coordination problems and the last contribution is a dynamic contracting problem in continuous time.

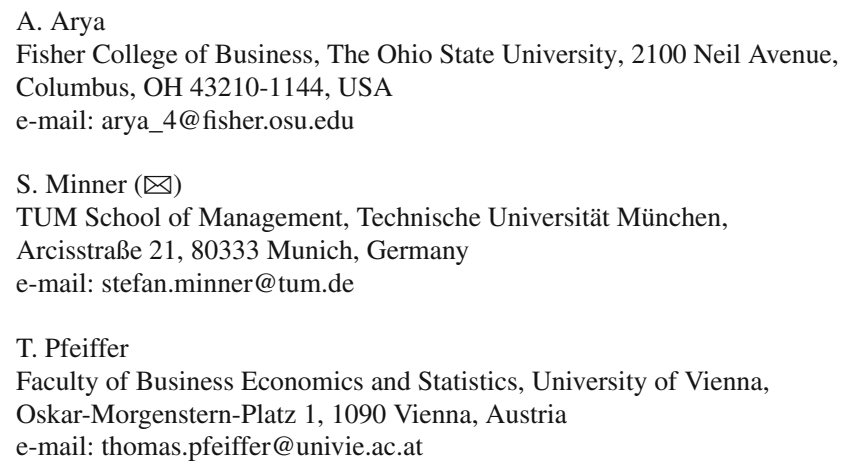


Chen, "Risk-incentives trade-off and outside options" analyzes a principal-agent problem with internal (projects) and external (outside-options) uncertainty and investigates the impact of heterogeneous degrees of risk aversions and uncertainty to explain competing results in the analysis of risk-incentive trade-offs. Larmande, "Voluntary Ambiguity in Incentive Contracts" investigates the effect of ambiguity where a principal can decide between ex-ante committing to an interpretation of accounting numbers or ex-post opportunistically choosing the least preferred interpretation for the agent. The optimal policy depends on the agent's degree of risk aversion. Krapp, Nebel and Sahamie, "Using forecasts and managerial accounting information to enhance closedloop supply chain management" present an approach for forecasting product returns in closed-loop supply chains based on Kalman filtering and a Bayesian approach. The robustness of the approach is compared against several other competing methods and the forecast accuracy is linked to the concept of economic value added. Brunner, "Wholesale price discrimination with interdependent retailers", analyzes a supply chain coordination problem with a wholesaler and two retailers who have the opportunity to invest into sales efforts that might cause free rider problems. Wholesale price discrimination can mitigate negative effects. Yan and Sun, "Coordinating loan strategies for supply chain financing with limited credit" present a three-player sequential game between a bank, a manufacturer and a retailer with decentralized operational and financial decisions under uncertainty. Under the risk of bankruptcy of the retailer, the manuscript analyzes credit lines and wholesale prices to coordinate the supply chain. Finally, El Ouardighi, Jørgensen and Pasin, "A dynamic game with monopolist manufacturer and price-competing duopolist retailers", present a classical dynamic, differential game for a supply chain coordination problem with a wholesaler and two competing retailers and characterizes the equilibrium for the resulting retail prices.

Anil Arya, Stefan Minner, Thomas Pfeiffer (Guest Editors) 